The Journal of Poultry Science, 44 : 19-28, 2007

\title{
Microsatellite Analysis of Genetic Diversity in Indian Chicken Populations
}

\author{
Nasrollah Pirany ${ }^{1}$, Michael N. Romanov ${ }^{2}$, Suhash P. Ganpule ${ }^{3}$, \\ Govindaiah Devegowda ${ }^{4}$ and Doddananjappa T. Prasad ${ }^{5}$ \\ ${ }^{1}$ Department of Animal Science, Faculty of Agriculture, University of Tabriz, \\ 29th Bahman Street, Tabriz, East Azarbayejan, Iran \\ ${ }^{2}$ Genetics Division, Conservation and Research for Endangered Species, Zoological \\ Society of San Diego, Arnold and Mabel Beckman Center for Conservation \\ Research, 15600 San Pasqual Valley Road, Escondido, CA 92027-7000, USA \\ ${ }^{3}$ Pioneer Group, Pongalur, Tamil Nadu, India \\ ${ }^{4}$ Department of Poultry Science, University of Agricultural Sciences, Bangalore, India \\ ${ }^{5}$ Department of Biotechnology, University of Agricultural Sciences, Bangalore, India
}

\begin{abstract}
Characterization of genetic diversity by employing molecular tools is a prerequisite in developing strategies for conservation and utilization of poultry genetic resources. We assessed genetic variation within and between six Indian chicken populations (Naked Neck, White Silkies, Commercial Layer and Broiler, Giriraja and Desi) using nine microsatellite markers. Seven loci were polymorphic in all populations, with the number of alleles varying from 3 to 27 per locus and 4.1 to 8.6 per population. Average heterozygosity and gene diversity in the populations were 0.68 and 0.66 , respectively. Some populations and loci deviated from Hardy-Weinberg equilibrium. Except Naked Neck, none of other populations was in genotypic disequilibrium for a single pairwise locus combination. $F$-statistics indicated that populations are genetically structured, $\sim 85 \%$ of the total genetic variation being due to genetic differentiation within the populations. Estimates of Latter's $F_{S T}$ and Nei's $D_{S}$ genetic distances revealed relatively close genetic similarity between Naked Neck and Giriraja, while White Silkies was the most distant. An estimated divergence time between Naked Neck and Giriraja was over100 years, with a comparatively longer (over 450 years) period of separation between Giriraja and White Silkies. We suggest that there is an essential room left for genetic improvement of Indian native breeds and commercial stocks.
\end{abstract}

Key words : chicken, genetic distance, genetic diversity, India, microsatellite markers

J. Poult. Sci., 44 : 19-28, 2007

\section{Introduction}

India and the neighboring countries have been referred to as one of the original homes of the Red Jungle Fowl (Gallus gallus), the progenitor of domesticated chickens. Although India has a rich heritage of native poultry germplasm, an estimated $80 \%$ of all poultry produced in India is now from foreign breeds (FAO, 1999), which urges decisive measures for conserving native genetic resources. To date, 21 native chicken breeds have been identified in India and a systematic effort should be pursued to characterize and preserve this biodiversity (Sapcota et al., 2002).

Received : April 14, 2006, Accepted : August 22, 2006

Correspondence to : Dr. M.N. Romanov, Genetics Division, Conservation and Research for Endangered Species, Zoological Society of San Diego, Arnold and Mabel Beckman Center for Conservation Research, 15600 San Pasqual Valley Road, Escondido, CA 92027-7000, USA

Tel : +1-760-291-5458 Fax : +1-760-291-5451 E-mail : mromanov@sandiegozoo.org 
Recent advances in molecular technology have opened up completely new horizons in assessment of genetic variability at the DNA level. During the last two decades, different classes of molecular markers have become available (see for review Weigend et al., 2004). Evaluation of genetic diversity within and between chicken populations in India has been undertaken mainly by using DNA fingerprints (Kumar et al., 1997 ; Sharma et al., 1999) and RAPD markers (Sharma et al., 1998 ; Kumar et al., 2000 ; Singh and Sharma, 2002). Application of microsatellite markers in assessment of the biodiversity levels in Indian poultry sector has been done to a limited extent. Wimmers et al. (2000) studied microsatellite profiles in four breeds including Naked Neck, Kadanath, Aseel and Frizzle in comparison with chickens from other countries, while Pandey et al. (2003) examined three native breeds, Nicobari, Aseel and Miri.
To improve our understanding on the nature of existing poultry biodiversity in India, we have further evaluated microsatellite variation in a broader set of native breeds and populations. Our specific objectives were to (1) assess genetic diversity within and among different Indian chicken populations including local breeds, commercial layers and broilers, and (2) show allelic patterns of microsatellite markers in the populations studied.

\section{Materials and Methods}

\section{Chicken Samples}

The 16 (eight of each sex) individuals were randomly sampled from each of the following chicken populations : Naked Neck (NN), Giriraja (GR), White Silkies (WS), Desi (DS), and one commercial broiler (CB) and one layer (CL) strains (Table 1). All but WS populations were relatively large breeding populations exposed (except WS and DS) to

Table 1. Description of the Indian chicken populations used in this study

\begin{tabular}{|c|c|c|c|}
\hline Population & $\begin{array}{c}\text { Abbreviation and } \\
\text { population size }\end{array}$ & Source & Origin, specific features, and production traits \\
\hline $\begin{array}{l}\text { Naked } \\
\text { Neck }\end{array}$ & $\mathrm{NN},>500$ & $\begin{array}{l}\text { Dept. of Poultry Science, } \\
\text { University of Agricultural } \\
\text { Sciences (UAS), Bangalore }\end{array}$ & $\begin{array}{l}\text { presumably originated in Malaysia ; found in hot and humid coastal regions } \\
\text { and northeastern region of India ; a medium-sized, dual-purpose strain bred as } \\
\text { a closed population using family selection ; has naked neck (gene } N A^{*} N A \text { ), } \\
\text { various plumage patterns and types of combs, and increased adaptability in hot } \\
\text { humid tropics ; body weight, } 1.4-1.6 \mathrm{~kg} \text { (hens), 2-3kg (cocks); egg number, } \\
75-90 \text { eggs in a year ; egg weight, } 40-50 \mathrm{~g}^{1}\end{array}$ \\
\hline Giriraja & $\mathrm{GR},>500$ & same as above & $\begin{array}{l}\text { a synthetic dual-purpose colored strain developed from } 1980-1989 \text { at UAS, } \\
\text { Bangalore, by crossing exotic broiler breeds (White Plymouth Rock, Red } \\
\text { Cornish and New Hampshire) and bred as a closed population using family } \\
\text { selection; has various plumage patterns, pea (gene } P^{*} P \text { ) and single }\left(R^{*} N \text { ) }\right. \\
\text { combs, brown and tinted eggs, and scavenging habits; adaptable to adverse } \\
\text { environment and resistant to diseases ; selected for growth and egg production ; } \\
\text { body weight ( } 8 \text { wks), } 1.6-1.7 \mathrm{~kg} \text {; egg number ( } 64 \text { wks), 140-150; egg weight, } \\
55-65 \mathrm{~g} \text {; non-broody }{ }^{2}\end{array}$ \\
\hline $\begin{array}{l}\text { White } \\
\text { Silkies }\end{array}$ & WS, $\sim 100$ & $\begin{array}{l}\text { imported to UAS from } \\
\text { Hyderabad Agricultural } \\
\text { University }\end{array}$ & $\begin{array}{l}\text { origin is uncertain ; presumably originated over } 700-2000 \text { years ago in China, } \\
\text { India or Japan ; kept at UAS as a small closed flock; bantam chickens, have } \\
\left.\text { white silky feathers (gene } H^{*} H\right) \text {, black skin and flesh }\left(F M^{*} F M\right) \text {, crest }\left(C R^{*}\right. \\
C R) \text {, muffs and beard }\left(M B^{*} M B\right) \text {, feathered feet }\left(P T I^{*} P T I\right) \text {, rose comb }\left(R^{*} R\right) \text {, } \\
\text { and five toes }\left(P O^{*} P O\right) \text {; body weight, } 0.74-1.25 \mathrm{~kg} \text {; egg number, } 120 \text { eggs in a } \\
\text { year }{ }^{3,4,5,6}\end{array}$ \\
\hline Desi & DS, $\sim 1000$ & a village near Bangalore & $\begin{array}{l}\text { a stock of primitive, unselected rural backyard fowls ; has small body size and } \\
\text { various phenotypic characters ; body weight ( } 8 \mathrm{wks}), 0.4-0.6 \mathrm{~kg} \text {; egg number } \\
(71 \mathrm{wks}), 65-70 \mathrm{eggs}^{2}\end{array}$ \\
\hline $\begin{array}{l}\text { Commercial } \\
\text { layer }\end{array}$ & $\mathrm{CL},>1000$ & $\begin{array}{l}\text { Venkateshwara Hatcharies } \\
\text { Ltd., Bangalore }\end{array}$ & a commercial egg-type strain bred under strong artificial selection \\
\hline $\begin{array}{l}\text { Commercial } \\
\text { broiler }\end{array}$ & $\mathrm{CB},>1000$ & same as above & a commercial broiler strain bred under strong artificial selection \\
\hline
\end{tabular}

References : ${ }^{1}$ Sapcota et al. (2002) ; ${ }^{2}$ Ramappa (2003 ; http : //indiaveterinarycommunity .com/profperspective/featuredarticle/dec-03/artramappa.asp) ; ${ }^{3}$ Hutt (1949) ; ${ }^{4}$ Tamada et al. (2004) ; ${ }^{5}$ Natural Health Center (http : //www.e2121.com/food_db/viewherb.php3?viewid $=$ 218) ; ${ }^{6}$ British Columbia Ministry of Agriculture and Lands (http : //www.agf.gov.bc.ca/aboutind/products/livestck/gamebird.htm). 
Table 2. Characterization of chicken microsatellite markers selected for the present study

\begin{tabular}{clcccc}
\hline \hline Batch code $^{1}$ & Locus & Chromosome & Repeat motif $^{2}$ & AT $\left({ }^{\circ} \mathrm{C}\right)^{3}$ & Size range $(\mathrm{bp})^{2}$ \\
\hline A & $A D L 0158$ & GGA10 & $(\mathrm{CA})_{12}$ & 50 & $189-217$ \\
A & $A D L 0278$ & GGA8 & $(\mathrm{TG})_{13}$ & 50 & $100-130$ \\
A & $M C W 0119$ & GGA20 & $(\mathrm{TG})_{8}$ & 50 & $114-180$ \\
B & $M C W 0005$ & GGA4 & $(\mathrm{TG})_{14}$ & 55 & $189-259$ \\
B & $M C W 0016$ & GGA3 & $(\mathrm{TG})_{16}$ & 55 & $134-163$ \\
B & $M C W 0029$ & GGA5 & $(\mathrm{TG})_{29}$ & 55 & $149-194$ \\
C & $M C W 0037$ & GGA3 & $(\mathrm{TG})_{8}$ & 50 & $155-159$ \\
C & $M C W 0069$ & GGA26 & $(\mathrm{TG})_{11}$ & 50 & $145-185$ \\
C & $M C W 0104$ & GGA13 & $(\mathrm{TG})_{16}$ & 50 & $191-230$ \\
\hline
\end{tabular}

${ }^{1}$ Triplet sets of the markers used for post-PCR pooling (refer to the Materials and Methods).

${ }^{2}$ According to the U.S. Poultry Genome Project Website (http : //poultry.mph.msu.edu/resources/ poptest1.htm) and Chicken Genome Mapping Site of Wageningen University (http : //137.224. 73.223/abg-org/hs/research/molecular/body_mcwtable.html).

${ }^{3}$ Annealing temperature used in this study following the optimized conditions.

family or individual selection. DNA was prepared from blood samples by proteinase $\mathrm{K}$ digestion and phenol chloroform extraction.

\section{Microsatellite Loci}

The nine highly polymorphic microsatellite markers were selected for genotyping (Table 2). Three of the microsatellite loci chosen (ADL0158, MCW 0005, $M C W 0016$ ) were initially recommended by the FAO/ISAG MoDAD Advisory Group and five more (ADL0278, MCW0016, MCW0037, MCW 0069, MCW0104) were included in the updated microsatellite list for biodiversity studies in chickens (http : // dad.fao.org; http : //www.msu.edu / romanoff / biodiversity / chickmicros. htm). The locus ADL0158 was also included in the Population Tester Kit (http://poultry.mph.msu.edu/resources /poptest1.htm). The $5^{\prime}$ ends of the forward microsatellite primers (or reverse one in the case of $M C W$ 0016) were labeled with one of the three fluorescence dyes (TET, HEX and FAM).

\section{PCR Procedure}

We used post-PCR multiplexing instead of coamplification of the markers. All of the PCR amplifications were performed in a $25 \mu \mathrm{l}$ reaction containing $50 \mathrm{ng}$ of the extracted DNA, $10 \mathrm{mM}$ Tris- $\mathrm{HCl}$ ( $\mathrm{pH} 9.0$ ), $50 \mathrm{mM} \mathrm{KCl}, 1.5 \mathrm{mM} \mathrm{MgCl}_{2}, 200 \mu \mathrm{M}$ of each dNTP (Sigma-Aldrich), 1.5 U of Taq polymerase (Bangalore Genei), 0.01\% gelatin and 6 pmol of each forward and reverse primers. The amplification was carried out in a thermocycler (PTC-100, MJ research, Inc., Watertown, MA, USA) using the following conditions : an initial denaturation step at $94^{\circ} \mathrm{C}$ for $3 \mathrm{~min}$ followed by 30 cycles of $95^{\circ} \mathrm{C}$ for $30 \mathrm{~s}$, annealing at $50-55^{\circ} \mathrm{C}$ (Table
2) for $45 \mathrm{~s}$, and $72^{\circ} \mathrm{C}$ for $90 \mathrm{~s}$, and a final extension of $10 \mathrm{~min}$ at $72^{\circ} \mathrm{C}$. Amplified microsatellite fragments were mixed in three loading multiplexes according to their size and fluorescent dye used, and were separated in a $6 \%$ denaturing gel using an ABI PRISM 377 automated sequencer (PerkinElmer, Applied Biosystems). The internal size standard TAMRA-500 (PerkinElmer) was used for sizing alleles. All gel images were analyzed using Genescan 3.5 and Genotyper 2.5 software programs.

\section{Statistical Analyses}

By comparing allele frequency at each locus and in each population, alleles were classified to the following groups : (a) private alleles, which are seen only in one population and are specific to that population, and (b) rare or absent alleles, which are not seen in one or more populations and are not specific to those populations. To characterize locus and population genetic variation, the observed $(\mathrm{Na})$, effective $(\mathrm{Ne})$ and private $(\mathrm{Npa})$ allele numbers, Shannon index $\left(H^{\prime}\right)$, heterozygosity (Ho, observed), gene diversity ( $G$, or expected heterozygosity), and total heterozygosity $\left(H_{T}\right)$ were calculated using GenAlEx software package (Peakall and Smouse, 2001). The Shannon's entropy, or Shannon's index, was originally devised in the information theory (Shannon and Weaver, 1949) and can be interpreted as the information gain expected in the performance of single measurement in the given population. Deviations from Hardy - Weinberg equilibrium (HWE) for each locus and each population were assessed using three methods: Chi-square, $G$-statistic and Fisher's exact (probability) test on a two-by-two contingency table. The complete enumeration method 
(Louis and Dempster, 1987) for loci with less than five alleles, and Markov's chain method (Guo and Thompson, 1992) for all other loci were performed using GENEPOP (Raymond and Rousset, 1995). Deviations from allelic linkage equilibrium for all pairwise locus combinations were tested using the exact probability test in GENEPOP.

Population differentiation was estimated using the variance-based method of Weir and Cockerham (1984) and $F$-statistics in FSTAT computer program (Goudet, 1995). Mean values of the $F$-statistics parameters, $F_{I T}, F_{S T}$ and $F_{I S}$, were obtained across loci (with $F_{I S}$ across populations only) by the Jackknifing procedure over loci (Weir, 1990). The GenAlEx computer program was used to identify the significance of differences in allele frequency distributions between samples by exact test of population differentiation, to estimate populations' pairwise weighted mean $F_{S T}$ (Weir and Cockerham, 1984), and to perform AMOVA tests with analogues of $F_{S T}$, significant proportion being estimated by 2000 replication bootstrapping procedure. Hereby, population differentiation was evaluated by analyzing differences in molecular data instead of Mendelian frequencies and by testing hypothesis under infinite allele model (IAM ; Excoffier et al., 1992). Sum of squares within populations (SSWP) further partitioned for each population and percentage of variation attributed to each population was determined.

Using Populations software package (Langella, 1999), Latter's $F_{S T}$ pairwise distances (Latter, 1972 ; Takezaki and Nei, 1996) and Nei's standard genetic distances $\left(D_{S}\right.$; Nei, 1972) were computed. Dendro- grams were constructed using Neighbor-Joining (NJ) method in PHYLIP package (Felsenstein, 1997), and bootstrapping of 2000 replicates over loci was performed in order to test the robustness of tree topology. The output trees were plotted using TREEVIEW (Page, 1996). Nei's genetic distance estimates were used to calculate the divergence time between the chicken populations based on the following equation (Nei, 1976) : $D_{S}=2 \alpha t$, where $\alpha$ is the assumed mutation rate of microsatellite loci ( 0.001 mutation per generation) and $t$ is time of divergence in generations that was converted to years in this study, given an average generation interval of nine months in chickens.

\section{Results}

\section{Genetic Diversity}

In total, 134 alleles were detected at nine microsatellite loci typed in 96 individual chickens. The mean number of alleles per locus was 14.9. The MCW0037 locus was monomorphic in the WS and CL populations and MCW0104 in CL. Number of observed alleles in all samples ranged from three at $M C W 0037$ to 27 at MCW0005 (Table 3). Table 4 represents the results of analysis for genetic parameters for each locus across the six populations. Effective number of alleles ranged from 2.1 at $M C W$ 0037 locus to 9.7 at $M C W 0029$. Total heterozygosity based on pooled allele frequencies across the populations was high and ranged from 0.53 for $M C W 0037$ to 0.90 for $M C W 0029$, with an average of 0.78 . The value of Shannon's index varied from 0.91 for $M C W$ 0037 to 2.66 for $M C W 0005$, with an average of 1.92 , and its trend was similar to the variation in $H_{T}$.

Table 3. Allelic patterns of microsatellite loci

\begin{tabular}{clr}
\hline \hline Maker name & \multicolumn{1}{c}{ Allele size range (bp) } & $N a^{*}$ \\
\hline ADL0158 & $161-164-176-178-180-182-186-187-\mathbf{1 8 9}-191-192-193-194-195-196-197-200-217-221-222$ & 20 \\
ADL0278 & $108-110-111-112-\mathbf{1 1 8}-120-122$ & 7 \\
MCW0119 & $105-107-111-113-115-\mathbf{1 1 7}-119-121-127-129-131-133-135$ & 13 \\
MCW0005 & $210-211-212-213-215-216-218-220-\mathbf{2 2 1}-222-225-231-235-236-237-241-242-244-245-247-$ & 27 \\
& $251-252-253-254-255^{1}-258-264$ & 11 \\
MCW0016 & $122-128-129-130-\mathbf{1 3 2}-134-136-138-140-142-146^{2}$ & 25 \\
MCW0029 & $132-141-142-148-\mathbf{1 5 0}-152-154-156-158-162-164-166-168-170-172-176-178-184-188-190-$ & \\
& $191^{3}-193-194-195$ & 3 \\
MCW0037 & $154-\mathbf{1 5 6}-158$ & 10 \\
$M C W 0069$ & $158-162-163-\mathbf{1 6 4}-166-168-170-172-174-176$ & 18 \\
$M C W 0104$ & $\mathbf{1 9 0}-196^{2}-198-200-202-203-204-206-208-210-212-216-220-222-224-226-228-23$ & \\
\hline
\end{tabular}

* Observed number of alleles.

Superscripts are private alleles with frequency over 0.1 in the populations : ${ }^{1} \mathrm{WS},{ }^{2} \mathrm{DS}$ and ${ }^{3} \mathrm{CL}$.

Most frequent allele for each locus is shown in bold. 
Table 4. Effective number of alleles $(\mathrm{Ne})$, total heterozygosity $\left(\mathrm{H}_{T}\right)$, gene diversity $(G)$, mean heterozygosity $(H o)$, fixation indices $\left(F_{I S}, F_{I T}\right.$ and $\left.F_{S T}\right)$ and Shannon's index $\left(H^{\prime}\right)$ for each locus across the populations studied

\begin{tabular}{lcccccccc}
\hline \hline \multicolumn{1}{c}{ Locus } & $N e$ & $H_{T}$ & $G$ & \multicolumn{1}{c}{$H o$} & \multicolumn{1}{c}{$F_{I S}$} & \multicolumn{1}{c}{$F_{I T}$} & \multicolumn{1}{c}{$F_{S T}$} & \multicolumn{1}{c}{$H^{\prime}$} \\
\hline$A D L 0158$ & 3.77 & 0.73 & 0.62 & 0.61 & 0.039 & 0.189 & 0.158 & 1.81 \\
$A D L 0278$ & 4.28 & 0.77 & 0.66 & 0.66 & 0.032 & 0.168 & 0.145 & 1.55 \\
$M C W 0005$ & 9.48 & 0.89 & 0.78 & 0.78 & 0.026 & 0.149 & 0.132 & 2.66 \\
$M C W 0016$ & 7.07 & 0.86 & 0.75 & 0.78 & -0.008 & 0.112 & 0.125 & 2.08 \\
$M C W 0029$ & 9.68 & 0.90 & 0.79 & 0.71 & 0.137 & 0.228 & 0.117 & 2.60 \\
$M C W 0037$ & 2.12 & 0.53 & 0.41 & 0.38 & 0.128 & 0.320 & 0.216 & 0.91 \\
$M C W 0069$ & 4.98 & 0.80 & 0.63 & 0.68 & -0.037 & 0.186 & 0.207 & 1.85 \\
$M C W 0104$ & 4.70 & 0.79 & 0.59 & 0.69 & -0.135 & 0.168 & 0.251 & 2.03 \\
$M C W 0119$ & 4.16 & 0.76 & 0.72 & 0.80 & -0.084 & -0.045 & 0.054 & 1.77 \\
Mean & 5.58 & 0.78 & 0.66 & 0.68 & 0.011 & 0.164 & 0.156 & 1.92 \\
\hline
\end{tabular}

Table 5. Mean ( $\mathrm{Na}$ ) and effective ( $\mathrm{Ne}$ ) number of alleles, heterozygosity ( $\mathrm{Ho}$ ), gene diversity $(G)$, fixation index $\left(F_{I S}\right)$, Shannon's index $\left(H^{\prime}\right)$, percentage of polymorphic loci $(\% P)$, number of polymorphic loci $(\mathrm{Np})$ and total number of private alleles $(\mathrm{Npa})$ as observed in six chicken populations at nine microsatellite loci

\begin{tabular}{cccccrcrcc}
\hline \hline Population & $N a$ & $N e$ & $H o(S E)$ & $G(S E)$ & \multicolumn{1}{c}{$F_{I S}$} & $H^{\prime}$ & $\% P$ & $N p$ & $N p a$ \\
\hline NN & 5.8 & 3.7 & $0.74(0.051)$ & $0.71(0.032)$ & -0.021 & 1.44 & 100.00 & 9 & 5 \\
WS & 4.8 & 3.4 & $0.56(0.086)$ & $0.58(0.088)$ & 0.069 & 1.15 & 88.89 & 8 & 8 \\
DS & 8.6 & 4.7 & $0.63(0.027)$ & $0.74(0.035)$ & 0.175 & 1.67 & 100.00 & 9 & 25 \\
GR & 6.4 & 4.0 & $0.73(0.027)$ & $0.74(0.022)$ & 0.040 & 1.53 & 100.00 & 9 & 9 \\
CL & 4.1 & 2.7 & $0.63(0.128)$ & $0.52(0.101)$ & -0.196 & 0.99 & 77.78 & 7 & 8 \\
CB & 6.2 & 3.6 & $0.76(0.070)$ & $0.69(0.035)$ & -0.067 & 1.42 & 100.00 & 9 & 4 \\
Mean & 6.0 & 3.7 & $0.68(0.031)$ & $0.66(0.026)$ & 0 & 1.37 & 94.44 & 8.5 & 9.8 \\
\hline
\end{tabular}

The CL population with 4.1 and WS with 4.8 alleles per locus had the lowest mean number of alleles across all the loci (Table 5). The greatest allelic diversity was observed in DS with the mean number of 8.6 alleles per locus. The effective number of alleles showed a similar variation pattern and ranged from 2.7 in CL to 4.7 in DS. Percentage of polymorphic loci was usually $100 \%$, except for CL with $77.8 \%$ and WS with $88.9 \%$. The CB population had only four private alleles, whereas DS possessed a maximum of 25 private alleles. Shannon's index also ranged from 0.99 in CL to a maximum of 1.67 in the DS population, with an average of 1.37 over all populations.

The heterozygosity, averaged over the nine loci for each population, ranged from 0.56 in WS to 0.76 in CB. As expected, the CL population had the lowest gene diversity, with a mean of 0.52 across the loci. Both DS and GR were characterized by the highest gene diversity with a mean of 0.74 .

The maximum and minimum $F_{I S}$ values between loci were found for $M C W 0005(0.137, P<0.01)$ and
MCW0104 ( $-0.135, P>0.05)$, respectively. Between the populations, DS had the highest $(0.175, P$ $<0.01)$ and $\mathrm{CL}$ the lowest $(-0.196, P<0.01) F_{I S}$ values.

Hardy-Weinberg Equilibrium and Genotypic Linkage Disequilibrium

The 54 HWE tests (nine loci by six populations) were performed and their results are presented in Table 6. Numbers of significant disequilibrium tests were eight, ten and five for Chi-square, $G$ - statistic and exact tests, respectively. The GR and DS populations did not show any deviations from HWE at a single locus, and no deviations were established at loci $A D L 0158, A D L 0278, M C W 0016, M C W 0037$ and $M C W 0069$ over all populations.

Genotypic disequilibria were assessed for all possible pairwise combinations of loci (36) in each population (data not shown). With the exception of the NN breed, all other populations showed significant deviations $(P<0.05)$ from genotypic equilibrium for a single pairwise locus combination. However, when all locus-by-locus pairwise comparisons 
Table 6. Summary of the three tests performed for HWE proportions for all locus-population combinations

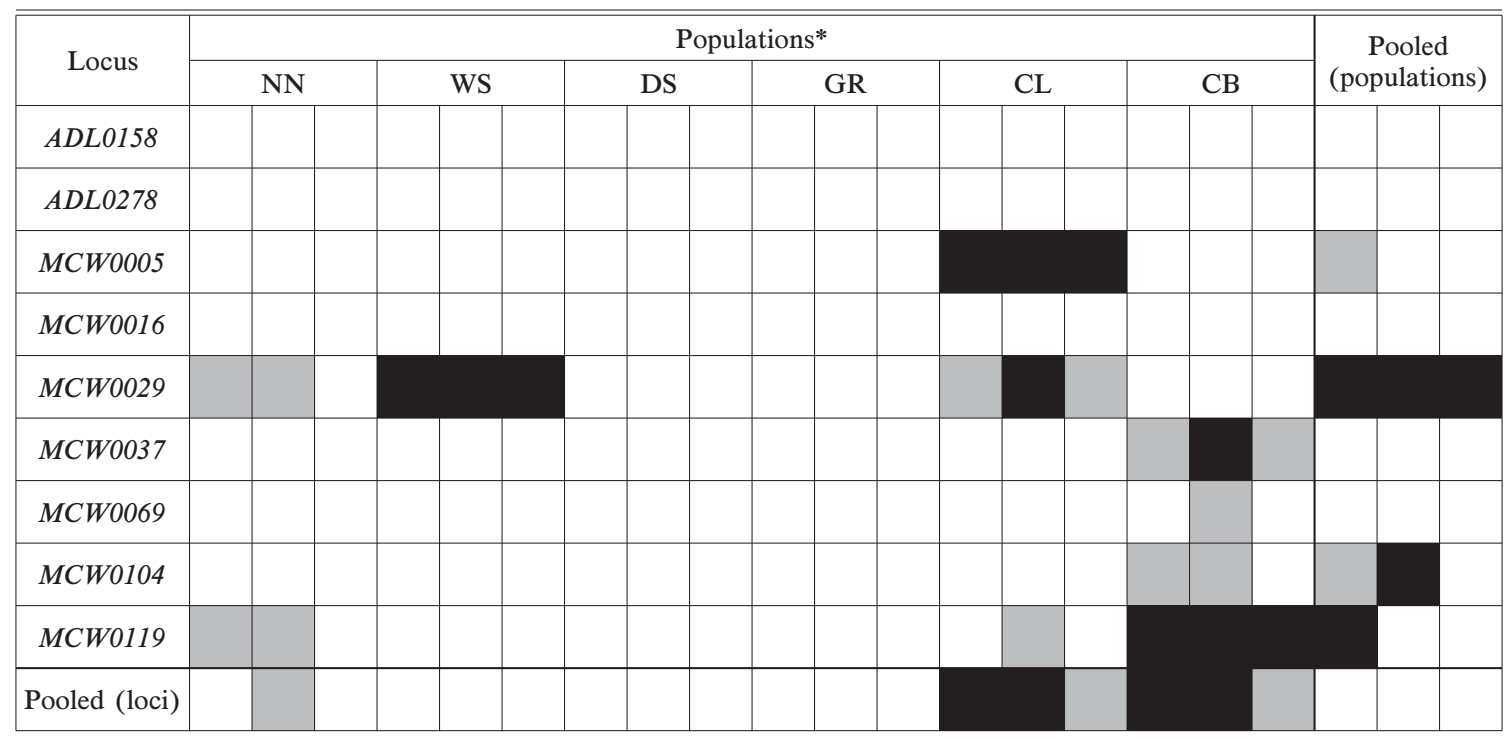

* The first cell in each population column reports the result of the Chi-square test, the second cell reports the result of the $G$-test, and the third cell contains the result of the Markov chain exact test. Black shading indicates deviations where $P<$ 0.01 and grey shading indicates deviations where $P<0.05$.

were pooled, none of the populations had significant deviations from genotypic equilibriums.

\section{Analysis of Locus and Population Differentiation}

The AMOVA test and partitioning of genetic variation under IAM for estimating proportion of $F_{S T}$ for each locus showed that loci MCW0104 (with $3 \%$ ) and MCW0119 (with 0.4\%) had the highest and the lowest percentage of variation, respectively, among the loci studied. As a result of the AMOVA test under IAM for each population, it was found that although most of the variation $(85 \%)$ was observed within populations, a significant proportion $(P<0.001)$ was attributable to differences between populations (Table 7). The DS population had the highest (18.6\%) and CL the lowest (13.0\%) percentage of variation within populations.

The lowest pairwise $F_{S T}$ (or co-ancestry) coefficient based on shared alleles was between $\mathrm{NN}$ and GR (0.052), and the highest between NN and CL $(0.23)$ as well as between GR and CL $(0.22$; all the values were significant at $P<0.01)$. The similar relatedness pattern was found out using Nei's standard genetic distance. The minimum and maximum distances were characteristic of the GR population : 0.171 between GR and NN, and 0.716 between GR and WS. As for CL, this population had the minimum (0.284) and maximum (0.696) genetic distances with the DS and GR populations, respectively (the distance matrices are not shown).

Using Latter's $F_{S T}$ and Nei's $D_{S}$ as genetic distance measures for the six populations studied, we attempted to reconstruct their relatedness. A NJ tree obtained from $F_{S T}$ genetic distance values demonstrated the close clustering of the $\mathrm{NN}$ and GR populations (with $80 \%$ bootstrap value) and a larger divergence between these two populations and the CL and DS populations (Fig. 1a). Figure $1 \mathrm{~b}$ shows a similar tree based on $D_{S}$ genetic distances, though bootstrap support was overall stronger than in the $F_{S T}$ tree. Three distinct clusters are recognizable in this tree. NN and GR (71\% bootstrap value) are close to each other and, then, to $\mathrm{CB}$ ( $51 \%$ bootstrap value), making the first cluster. The DS and CL populations (54\% bootstrap value) are in the second cluster, WS being a single separate and the most remote group in the both trees.

The approximate divergence times between populations were calculated based on Nei's standard genetic distance, with a maximum estimate for GR and WS (over 450 years) and a minimum one for NN and GR (over 100 years).

\section{Discussion}

The number of alleles identified at each locus for each population is considered to be a good indicator of genetic variability (Nevo, 1978). Compared to 
Table 7. AMOVA analysis of microsatellite variation for six chicken populations under IAM.

\begin{tabular}{lrrrrrrr}
\hline \hline \multicolumn{1}{c}{ Source } & d.f. & \multicolumn{1}{c}{ SS } & \multicolumn{1}{c}{ MS } & VC & \% Total & \multicolumn{1}{c}{$F_{S T}$} & $P$ \\
\hline Among populations & 5 & 103.29 & 20.66 & 0.55 & 15 & 0.153 & $<0.001$ \\
Within populations & 186 & 571.59 & 3.07 & 3.07 & 85 & & \\
Total & 191 & 674.88 & 23.53 & 3.62 & 100 & & \\
\hline
\end{tabular}

The $P$ value was calculated by 1000 replication bootstrap among populations (based on number of alleles). d.f., degree of freedom; SS, sum of squares; MS, mean squares; VC, variance component ; $P$, probability level.

previously published data, results of this investigation (except for $M C W 0037$ ) revealed equal (in the case of $A D L 0278$ ) or much greater microsatellite allele variation in chickens. Three loci in this study, $A D L 0278, M C W 0037$ and $M C W 0069$, were also analyzed within the AVIANDIV project (http : // w3.tzv.fal.de/aviandiv/index.html) and had similar numbers of alleles in a subset of 20 breeds (Rosenberg et al., 2001), while being less polymorphic in comparison with a total of 52 various populations employed (Hillel et al., 2003).

Seven microsatellite loci were polymorphic in all the populations, while $M C W 0037$ locus was monomorphic in WS and CL, and MCW0104 in CL. Monomorphic loci have been seen in a variety of populations especially layer lines (Crooijmans et al., 1996 ; Vanhala et al., 1998). Variation in allele number and size ranges was the least in CL and similar to the reported values in other commercial breeds and lines. This low polymorphism could be due to strong selection in the commercial layer lines. The most variable was the DS population that had the greatest numbers of alleles and private alleles. This may be explained by the fact that the indigenous rural chickens are mixed groups of birds that randomly mate, have different origin and genetic background, and may occasionally interbreed with other breeds and even wild jungle fowls.

Most populations had one or more private alleles. The maximum (25) and minimum (4) of population specific alleles were seen in the DS and CB populations, respectively. Breed specific alleles have been noted by other investigators (Romanov and Weigend, 2001 ; Rosenberg et al., 2001 ; Hillel et al., 2003).

On the whole, there was a high level of genetic variation detected in the study, the average weighted unbiased heterozygosity calculated over all six populations being 0.78. Crooijmans et al. (1996) reported an average heterozygosity of 0.42 in a survey of 17
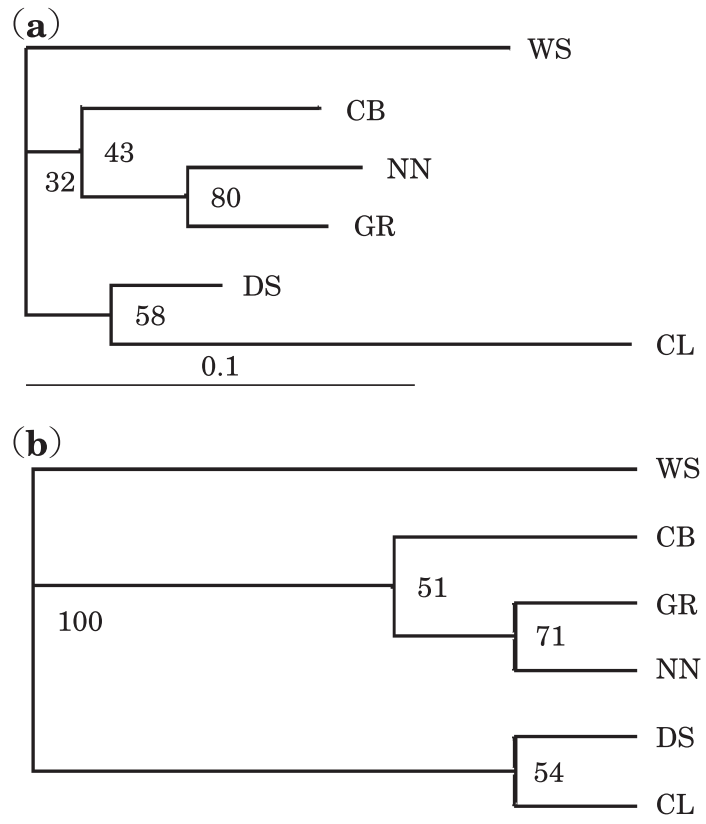

Fig. 1. Dendrograms of genetic relationships between six Indian chicken populations as reconstructed by the NJ method using (a) $F_{S T}$ (Latter, 1972 ; Takezaki and Nei, 1996) and (b) $D_{S}$ (Nei, 1972) distances. The dendrograms are plotted as (a) a phylogram, with a scale bar for branch lengths, and (b) a rectangular cladogram, with the same length of the branches. Numbers on the nodes are percentage bootstrap values from 2000 replications of resampled loci.

NN : Naked Neck, GR : Giriraja, WS : White Silkies, DS : Desi, CB : commercial broiler strain, CL : layer strain. See Table 1 for the origin of the populations.

microsatellites typed in 15 highly selected broiler and layer lines. Vanhala et al. (1998) reported heterozygosity from 0 to 0.91 for eight Finnish chicken lines using nine microsatellite markers, and van Marlé-Köster and Nel (2000) from 0.314 to 0.612 for native African chickens. Hillel et al. (2003) studied biodiversity of 52 European chicken populations by exploiting 22 dinucleotide micro- 
satellite markers, and an average gene diversity was 0.48. The level of gene diversity obtained in this study $(0.52$ to 0.74 , mean $G=0.66)$ was in agreement with that found in Indian breeds $(0.63$ to 0.71 , Wimmers et al., 2000 ; 0.51 to 0.88, Pandey et al., 2003) and in Chinese populations (0.76, Zhang et al., 2002).

In our study, the CL $(G=0.52)$ and WS $(G=$ 0.58 ) chickens were found to be less variable than others, especially DS and GR. Unlike CL, the WS population has not been subject to intense selection but its lower level of genetic variation is mostly related to high inbreeding values because of small number of birds in the flock. In contrast, greater gene diversity was discovered by Zhang et al. (2002) in two other Chinese Silkie varieties, Taihe Silkies (0.75) and Black Silkies (0.77), using nine microsatellite markers. Gene diversity in CB (0.69) was greater than or similar to that in other broiler lines (0.53-0.67 ; Crooijmans et al., 1996 ; Vanhala et al., 1998 ; Hillel et al., 2003). We suggest that the established breed differences in genetic variation presumably reflect the consequences of artificial selection (CL), genetic isolation (WS) and breed admixture (CB, NN, GR and DS). On the other hand, heterozygosity levels can be drastically affected by previous population dynamics and resulted from sampling error associated with the breeding program of these populations.

A few populations displayed significant deviations from HWE when results from all nine loci (none of them are on sex chromosomes) were pooled (Table 6). This may reflect genetic substructure within breeds, particularly in the case of the CL and CB, and might be an evidence of selection or an indication of the presence of null alleles (Callen et al., 1993). Conversely, if a population deviates significantly from HWE at a number of independent loci, it may actually be composed of discrete demes, subject to migration from an external source or is perhaps undergoing non-random mating. None of the populations was in genotypic disequilibrium, which was expected due to a wide distribution of the used microsatellite markers across the chicken genome.

Calculation of $F_{S T}$ estimators of genetic subdivision indicated that there was a high level of interpopulation genetic variation observed among studied populations, presumably reflecting their divergent origins, and this information will be useful in further studies of genetic differentiation in Indian chickens. The AMOVA tests under IAM mutational model showed that most of the variation in the chicken populations was present within populations $(85 \%)$, while a significant degree of differentiation among populations $(15 \%)$ was also observed.

The chicken populations included in this study clearly diverged from each other. Both distances (Latter's $F_{S T}$ and Nei's $D_{S}$ ) showed a close relation between NN and GR, with bootstrap values averaged at $76 \%$. Based on the history of the GR population developed as a synthetic strain (Loknath and Murthy, 2002), a close relationship between NN and GR is not so far clear, although both NN and GR are recognized as dual-purpose meat-type breeds (Loknath and Murthy, 2002 ; Sapcota et al., 2002). Further, both distances clustered CB with $\mathrm{NN}$ and GR, though the average bootstrap value being not supportive (47\%). However, the similarity between GR and CB is expected, since the breeds used in designing GR (Loknath and Murthy, 2002) were those represented as maternal or paternal lines in the commercial broilers, or they were perhaps selected for the same traits, such as body size or growth. The CL and DS populations are characterized by a lower body weight that might somehow be related to their allele profiles at the nine microsatellite loci studied and subsequently to their clustering, though the average bootstrap support value in both trees was low $(56 \%)$. The WS chickens are distinct from the other chicken breeds in that they have silky plumage, purple-colored skin and the bluish meat, purple to dark blue colored wattles, beak and comb, and five toes. Concerning the origin of the Silkie fowl, it has been considered that the breed originated in India and was also established in China and Japan but its original habitat in Asia has not been clarified (Tamada et al., 2004). As a whole, the tree topology for the six Indian populations seems to be plausible and would reflect their subdivision into three groups : (1) dual-purpose and meat-type strains with the highest heterozygosity (NN, GR, CB), (2) chickens with a lower body weight and heterozygosity (CL, DS), and (3) an old native breed with the lowest heterozygosity (WS).

The more divergent populations are GR and WS, with an estimate of more than 450 years since their ancestors formed separate lineages, which is con- 
cordant with historical evidences that WS has been seen around for 700 or even more years. However, further studies are necessary to find out the exact divergence times between present-day chicken breeds.

In conclusion, there is a substantial room for improvement within Indian native breeds. A wide genetic diversity of Indian native chickens found in this and other studies (e.g. Pandey et al., 2003) is a critical component for future selection and development of quality chicken breeding in India. The results of our investigation are in agreement with opinions that there is also enough genetic variation in commercial stocks to generate further progress in the years ahead (Flock, 1994) and that the biological limits for broiler breeders and layers have not yet been encountered (Barton, 1994).

\section{Acknowledgments}

We acknowledge the Ministry of Science, Research and Technology of the Islamic Republic of Iran and University of Tabriz for providing N.P. with an opportunity for higher education in India. Sincere thanks are also due to Dr. E. Hajizadeh and Dr. M. Kafi, former and present Heads of the Science and Education Section, Embassy of Iran, for their precious help and support to N.P. during his research in India. The completion of this research was impossible without microsatellite primers that were synthesized and provided with support from NAGRP (USDA-CSREES, NRSP-8), a generous gift from Hy-Line International and in-kind support for Poultry Genome Coordination from the USDAARS Avian Disease and Oncology Laboratory (ADOL) and Michigan State University. We will never forget kindness of Dr. H. Hans Cheng (ADOL) for sending several batches of those primers.

\section{References}

Barton NF. Breeding meat type poultry for the future : targets for selection, limits to performance and market requirements for chicken. In : Proceedings of the 9th European Poultry Conference, Vol. I. pp. 33-38. The United Kingdom Branch of the WPSA. Glasgow. 1994.

Callen DF, Thompson AD, Shen Y, Phillips HA, Richards RI, Mulley JC and Sutherland GR. Incidence and origin of "null" alleles in the (AC)n microsatellite markers. American Journal of Human Genetics, 52 : 922-927. 1993.

Crooijmans RPMA, Groen AF, van Kampen AJA, van der Beek S, van der Poel JJ and Groenen MAM. Microsatellite polymorphism in commercial broiler and layer lines estimated using pooled blood samples. Poultry Science, 75 : 904-909. 1996.

Excoffier L, Smouse PM and Quattro JM. Analysis of molecular variance inferred from metric distances among DNA haplotypes : application of human mitochondrial DNA restriction data. Genetics, 131 : 479-491. 1992.

FAO. 1999. The Global Strategy for the Management of Farm Animal Genetic Resources. Executive Brief. Food and Agriculture Organization of the United Nations. Rome (available online at http : //dad.fao.org/en/ refer/library/idad/ex-brf.pdf).

Flock DK. Targets for selection, limits to performance and market requirements for chicken : Eggs. In : Proceedings of the 9th European Poultry Conference. The United Kingdom Branch of the WPSA. Glasgow. Vol. 1. pp. 27-32. 1994.

Goudet J. FSTAT version 1.2 : a computer program to calculate F-statistics. Journal of Heredity, 86 : 485-486. 1995.

Guo S and Thompson E. Performing the exact test of HardyWeinberg proportions for multiple alleles. Biometrics, 48 : 361-372. 1992.

Hillel J, Groenen MAM, Tixier-Boichard M, Korol AB, David L, Kirzhner VM, Burke T, Barre-Dirie A, Crooijmans RPMA, Elo K, Feldman MW, Freidlin PJ, Mäki-Tanila A, Ortwijn M, Thomson P, Vignal A, Wimmers $\mathrm{K}$ and Weigend S. Biodiversity of 52 chicken populations assessed by microsatellite typing of DNA pools. Genetics Selection Evolution, 35 : 533-557. 2003.

Hutt FB. Genetics of the Fowl. McGraw-Hill. New York. 1949.

Kumar S, Singh RK, Dhara AK, Rahwat AK and Johari DC. Isoschizomeric restriction profiles of Indian fowl genome. Indian Journal of Poultry Science, 32 : 119121. 1997.

Kumar S, Kumar KG and Singh D. Evaluation of generic biodiversity in White Leghorn chicken lines using RAPD-PCR. In : XXI World's Poultry Congress : Abstracts and Proceedings, CD-ROM. WPSA. Montreal. 2000 .

Langella O. Populations 1.2.28 (12/5/2002), CNRS UPR 9034. Laboratoire Population Génétique et Evolution, Centre National de la Recherche Scientifique (CNRS). Gif-sur-Yvette. 1999.

Latter BDH. Selection in finite populations with multiple alleles. III. Genetic divergence with centripetal selection and mutation. Genetics, 70 : 475-490. 1972.

Loknath GR and Murthy HNN. Breeding birds for field and scavenging conditions. In : Proceedings of the $2 \mathrm{nd} \mathrm{Na}$ tional Seminar on Rural Poultry for Adverse Environment. University of Agricultural Sciences. Bangalore. pp. 42-46. 2002.

Louis E and Dempster E. An exact test for Hardy-Weinberg and multiple alleles. Biometrics, 43 : 805-811. 1987.

Nei M. Genetic distances between populations. American Naturalist, 106 : 283-292. 1972.

Nei M. Mathematical models of speciation and genetic distance. In : Population Genetics and Ecology (Karlin S and Nevo E eds.). Academic Press. New York. pp. 723- 
765. 1976.

Nevo E. Genetic variation in natural populations : patterns and theory. Theoretical Population Biology, 13 : 121177. 1978 .

Page RDM. TreeView : An application to display phylogenetic trees on personal computers. Computer Applications in the Biosciences, 12 : 357-358. 1996.

Pandey AK, Mishra B, Chaudhary P, Tantia MS and Jijh RK. Microsatellite analysis in three breeds of Indian poultry. Indian Journal of Animal Sciences, 73 : 788792. 2003.

Peakall R and Smouse PE. GenAlEx V5 : Genetic Analysis in Excel. Population Genetic Software for Teaching and Research. Australian National University. Canberra. 2001.

Ramappa BS. Giriraja - miracle fowl for rural poor. Published online by India Veterinary Community. com. 2003.

Raymond $\mathrm{M}$ and Rousset F. GENEPOP (version 1.2) : population genetics software for exact tests and ecumenicism. Journal of Heredity, 86 : 248-249. 1995.

Romanov MN and Weigend S. Analysis of genetic relationships between various populations of domestic and jungle fowl using microsatellite markers. Poultry Science, 80 : 1057-1063. 2001.

Rosenberg NA, Burke T, Feldman MW, Freidlin PJ, Groenen MAM, Hillel J, Mäki-Tanila A, TixierBoichard M, Vignal A, Wimmers $\mathrm{K}$ and Weigend $\mathrm{S}$. Empirical evaluation of genetic clustering methods using multilocus genotypes from 20 chicken breeds. Genetics, $159:$ 699-713. 2001.

Sapcota D, Islam $\mathrm{R}$ and Sheikh IU. Conserving poultry biodiversity in India. Livestock International, $6: 21-23$. 2002.

Shannon CE and Weaver W. The Mathematical Theory of Communication. University of Illinois Press. Urbana. 1949.

Sharma D, Appa Rao KBC and Totey SM. Estimation of genetic diversity among various breeds of poultry using randomly amplified polymorphic DNA. In : Proceedings of the 10th European Poultry Conference. WPSA. Jerusalem. Vol. I. pp. 259-262. 1998.

Sharma D, Appa Rao KBC and Rawat AK. Restriction enzyme analysis of satellite DNA components from poultry genome. Indian Journal of Animal Sciences, 69 : 711-714. 1999.

Singh RV and Sharma D. Within- and between-strain variability in White Leghorn population detected through RAPD markers. British Poultry Science, 43 : 33-37. 2002.

Takezaki N and Nei M. Genetic distances and reconstruction of phylogenetic trees from microsatellite DNA. Genetics, 144 : 389-399. 1996.

Tamada Y, Nishibori M, Yasue H and Wada Y. Polymorphism of mitochondrial D-loop region of Silkie fowls. In : Proceedings of the 29th International Conference on Animal Genetics. International Society for Animal Genetics, Japanese Society of Animal Breeding and Genetics. Tokyo. p. 96. 2004.

van Marlé-Köster E and Nel LH. Genetic characterization of native Southern African chicken populations : evaluation and selection of polymorphic microsatellite markers. South African Journal of Animal Science, 30 : 1-6. 2000.

Vanhala T, Tuiskula-Haavisto M, Elo K, Vilkki J and MäkiTanila A. Evaluation of genetic variability and genetic distances between eight chicken lines using microsatellite markers. Poultry Science, 77 : 783-790. 1998.

Weigend S, Romanov MN, Ben-Ari G and Hillel J. Overview on the use of molecular markers to characterise genetic diversity in chickens. In : World's Poultry Congress and Exhibition. Participant List and Full Text CD. WPSA - Turkish Branch. Istanbul. 2004.

Weir BS. Genetic Data Analysis. Sinauer. Sunderland. 1990.

Weir BS and Cockerham CC. Estimating F-statistics for the analysis of population structure. Evolution, 38 : 13581370. 1984.

Wimmers K, Ponsuksili S, Hardge T, Valle-Zarate A, Mathur PK and Horst P. Genetic distinctness of African, Asian and South American local chickens. Animal Genetics, 31 : 159-165. 2000.

Zhang X, Leung FC, Chan DKO, Chen Y and Wu C. Comparative analysis of allozyme, random amplified polymorphic DNA, and microsatellite polymorphism on Chinese native chickens. Poultry Science, 81 : 10931098. 2002. 